\section{Overactive bladder syndrome in the ageing population}

\author{
Steven Mark Finney, lan Eardley \\ Pyrah Department of Urology, St, \\ James's University Hospital, Leeds, UK
}

\begin{abstract}
Overactive bladder syndrome $(\mathrm{OAB})$ is a common problem in the older age group that can seriously effect quality of life. It raises challenges in the assessment and treatment of the patient with attention needed to be given to the presence of co-existent disease, cognition, patient motivation and the potential negative effects of pharmacological treatment. Though with the correct approach a substantial amount patients should derive some benefit.
\end{abstract}

\section{Introduction}

The overactive bladder syndrome (OAB) is a symptom complex characterised by urgency, with or without urge incontinence, usually accompanied by frequency and nocturia, in the absence of other pathology such as infection or stones. ${ }^{1}$ It can be a disabling condition that has been shown to significantly impact upon quality of life, quality of sleep and mental health. ${ }^{2}$ Many patients, especially the elderly, defer seeking advice due to either embarrassment or the misconception that nothing can be done for the condition as it is seen as part of the normal ageing process. ${ }^{3,4}$ Those who do present earlier may do so, not necessarily as a direct result of their urinary symptoms as such, but as a result of underlying concerns about what the symptoms may represent. Men in particular may mistakenly associate their lower urinary tract symptoms to prostate disease and be subsequently concerned about the risk of malignancy.

The impact of overactive bladder syndrome on the elderly can vary considerably between individuals. As a group the ageing population is diverse in nature, ranging from fit mobile individuals through to those less mobile with significant co-morbidities. As such the ability to cope with the condition and associated treatments can vary considerably. In some cases incontinence can result in skin breakdown, with its own associated complication, urinary tract infection, an increased risk of falls, feelings of alienation and avoidance behaviour. ${ }^{5}$ The consequences of $\mathrm{OAB}$ can affect patients and carers alike. Incontinence is the second most common reason for admission to long term care; second only to demen- tia. $^{6}$

Thus OAB is a significant problem in the ageing population that can have far reaching ramifications. The aim of this review is to explore current understanding of the condition in addition to current managements.

\section{Extent of problem}

Overactive bladder syndrome is a common condition, affecting nearly 100 million people in the western world ${ }^{2,7}$ and although not life threatening it seriously affects quality of life and ability to work/ function. The lower urinary tract symptoms associated with $\mathrm{OAB}$ become more prevalent in the aging population, where approximately $40 \%$ over the age of 75 years are affected; $41 \%$ of men and $31 \%$ of women. ${ }^{7}$ Therefore, $\mathrm{OAB}$ represents a major problem to individuals, health professions and society alike. More importantly however, as the population within the Western world is generally ageing, those affected by $\mathrm{OAB}$ is set to increase significantly. Within the European Union current population forecasts, based upon current birth and mortality rates, predict the proportion of people aged $>65$ years to increase from $17.1 \%$ to $30.0 \%$ with absolute numbers rising from 83.6 million in 2008 to 151.5 million in 2060. However, the greatest proportion increase is in those aged $>80$ years with a projected tripling of numbers from 21.8 million in 2008 to 61.4 million in 2060.8 The total economic cost of this collection of $\mathrm{OAB}$ symptoms is high. In 2007 the costs in the USA were approximately $\$ 65.9$ billion with these set to rise to a predicted $\$ 76.2$ billion and $\$ 82.6$ billion in 2015 and 2020, respectively. ${ }^{9}$ Though these figures are generally accepted to be an underestimate due to under reporting of the condition.

\section{Nature of problem}

The primary clinical problem behind $\mathrm{OAB}$ is urgency, described as the complaint of a sudden compelling desire to pass urine which is difficult to defer. ${ }^{1}$ Remarkably, despite the prevalence and costs involved, the mechanisms underlying increased urge are not fully understood. In the vast majority of cases where patients with $\mathrm{OAB}$ are studied using conventional urodynamics sensations of urgency correlate with rises in intra-vesical pressure, a condition classified as detrusor over activity (D0). In a proportion of patients however, sensations of urgency are not accompanied by pressure changes, described as sensory urgency. The differences seen in the relationship between sensation and overactive detrusor activity may be indicative of different clinical states. Alternatively, it may represent the fact that the nature of the clinical condition is not fully appreciated. What is known, however, is that older people tend to develop more severe disease than younger people. Studies
Correspondence: Steven Mark Finney, Pyrah Department of Urology, St. James's University Hospital, Beckett St., Leeds, UK, LS9 7TF. Tel. +44.113.2066994 - Fax: +44.113.2064920. E-mail: s.mfinney@doctors.org.uk

Key words: medicine, gynaecology, urology, overactive bladder syndrome, elderly.

Received for publication: 14 September 2011. Accepted for publication: 11 October 2011.

This work is licensed under a Creative Commons Attribution NonCommercial 3.0 License (CC BYNC 3.0).

(C) Copyright S.M. Finney and I. Eardley, 2011

Licensee PAGEPress, Italy

Urogynaecologia 2011; 25:e12

doi:10.4081/uij.2011.e12

using urodynamic parameters show that older people with detrusor overactivity have reduced bladder capacities and tend to develop urgency at lower volumes than their younger counterparts. Conversely, older adults with no demonstrable detrusor overactivity have reduced sensation during bladder filling. ${ }^{10}$

A number of studies have been performed to examine the age related changes in the structure of the ageing bladder in an attempt to relate these to differences in function. In aged human bladder strips a decrease in acetylcholine (ACh) and an increase in adenosine triphosphate (ATP) release is seen from postganglionic parasympathetic axons innervating the bladder. ${ }^{11}$ Similar responses are seen in animal models with the suggestion that the mechanisms involved in the underlying increase in ATP and inhibition of ACh are calcium dependent. ${ }^{12}$ Further evidence suggesting that these findings are of physiological significance is illustrated by a reduction in muscarinic receptors seen within the detrusor muscle of older men with an associated selective decrease in muscarinic M3 receptor mRNA in both men and women. However, no decrease in muscarinic M2 receptor mRNA is seen. ${ }^{13}$ Though these findings may illustrate part of the patho-physiology behind the development of $\mathrm{OAB}$ in the elderly it must be emphasised that, in comparison to their younger counterparts, the aetiology behind $\mathrm{OAB}$ is likely to be more multi factorial in nature. Co-morbidities, overall cognitive ability and mobility are all likely to play a role in the severity and impact of the condition. Certainly, it has been shown that $\mathrm{OAB}$ with or without leakage is considerably more common amongst patients with cancer, diabetes, congestive heart failure or neurogenic disorders. ${ }^{2}$ Older patients are also more likely to have a reduced bladder capacity and be less able to suppress involuntary contractions of the bladder. ${ }^{14}$ 
The consequences of $\mathrm{OAB}$ syndrome extend beyond that of the inconvenience created by its symptoms. They can have a detrimental effect upon quality of life in addition to negative economic effects. Urinary incontinence has been shown to be a significant risk factor associated with falls in all environments; ${ }^{14-16}$ increasing the risk of injuries and fractures. Furthermore, it has also been shown to be associated urinary tract infections, sleep disorders and depression. ${ }^{17}$

\section{Transient overactive bladder /incontinence}

Symptoms of $\mathrm{OAB}+/$ - incontinence can also be transient in nature. Potentially reversible causes of which are best recalled by the mnemonic DIAPPERS. Approximately 33\% of community dwelling elderly and more than half of those who are hospitalised develop transient incontinence. $^{18}$

D - Delirium and confusion related symptoms require treatment of the underlying cause rather than bladder management.

I - Infection of the urinary tract (UTI) can cause the symptoms associated with $\mathrm{OAB}$, namely urgency and frequency. Asymptomatic bacteruria does not. ${ }^{19}$

A - Although previously thought to cause incontinence current consensus of opinion suggests that Atrophic vaginitis does not cause urinary incontinence. ${ }^{20}$ However, it is possible that the symptoms of $\mathrm{OAB}$ are symptoms of urogenital atrophy in older post-menopausal women. ${ }^{21,22}$ A systematic review of the effects of oestrogen on symptoms suggestive of $\mathrm{OAB}$ concluded that oestrogen therapy may be effective in alleviating $\mathrm{OAB}$ with local administration being the most beneficial route of administration. ${ }^{23}$ Furthermore, OAB is also a risk factor for urinary tract infection which in itself can result in symptoms of $\mathrm{OAB} .^{24}$

$\mathrm{P}-$ Pharmaceuticals such as diuretics, sedative hypnotics and those with antimuscarinic or adrenergic effects may increase the risk of incontinence + - associated symptoms of OAB.

$\mathrm{P}$ - Psychological effects related to factors such as depression, anxiety or neurosis can result in symptoms of $\mathrm{OAB}$.

$\mathrm{E}$ - Excess urine production through increased fluid intake, diuretics or metabolic disorders can lead to frequency. Furthermore, conditions such as congestive heart failure can lead to nocturia.

$\mathrm{R}$ - Restricted mobility commonly exacerbates the consequences of $\mathrm{OAB}$ in the elderly leading onto to increased episodes of incontinence.

S - Stool impaction has been shown to stimulate opioid receptors in cats resulting in decreased bladder activity ${ }^{25}$ leading to symptoms of $\mathrm{OAB} /$ overflow incontinence.

\section{Patient assessment}

Due to the relatively high prevalence of $\mathrm{OAB}$ in the elderly active attempts should be made to identify and screen those at risk. The aims should be to confirm the diagnosis, identify potentially treatable underlying causes, assess severity and impact upon quality of life, and to ensure that there are no red flags warranting further investigation.

\section{History}

Key areas of the history focus upon urinary and bowel symptoms, fluid intake, identification of co-morbidities and drugs that may exacerbate the problem, and the social history. Furthermore, patients and carers should be asked about the bothersome of symptoms, their expected goals for treatment, and likely co-operation with treatment. Certain symptoms raise the possibility of other conditions. Dysuria may indicate underlying urinary tract infection whilst supra-pubic/bladder pain may raise the possibility of carcinoma in situ.

A history of visible haematuria should be referred for further investigation to exclude malignancy. Nocturia in the presence of daytime symptoms suggests an underlying urological cause (e.g. elevated post void residual). However, in the absence of daytime symptoms causes related to nocturnal polyuria and sleep disturbances need to be considered, though occasionally high pressure chronic retention can present solely with nocturia.

\section{Examination}

A general abdominal examination should be performed paying attention to whether the bladder is palpable in addition to rectal examination. The introitus should be inspected for vaginal atrophy and an examination performed to assess pelvic tone and bladder neck descent. The patients mobility and cognitive function should also be assessed.

\section{Basic investigations}

Three day voiding diaries which include fluid intake, voiding times, amount voided and the times of retiring to bed and waking in the morning are invaluable in the assessment of these patients. Urinalysis may exclude urinary tract infection. Other abnormalities such as non-visible haematuria, glycosuria or poteinuria require further investigation. A post void residual (PVR) volume estimation is also useful but there is no clear consensus as what constitutes a high post void residual. Though it is suggested that post void volumes of $>200$ $500 \mathrm{~mL}$, in whom the PVR is thought to be the major contributor may benefit from a period of catheterisation.

\section{Further investigations}

\section{Urodynamics}

Urodynamics are not usually required in the assessment of cases of overactive bladder syndrome where conservative management would be required since the absence of detrusor overactivity will not generally influence treatment since; $\mathrm{OAB}$ is a clinical diagnosis. However, urodynamics should be considered should there be extreme doubt as to the diagnosis. But in general urodynamic testing is reserved for patients prior to procedures for stress incontinence. Though many clinicians perform urodynamics in more extreme cases of $\mathrm{OAB}$ where intravesical botulinum toxin injections would be considered.

\section{Treatments}

\section{Lifestyle and behavioural modification}

The evidence base to support lifestyle modification is poor and at times can be contradictory. Obesity has been shown to be associated with an increased risk of stress and urge related leakage. ${ }^{26}$ Though further studies have shown that weight loss, in obesity, does not improve symptoms of urge related leakage, ${ }^{27,28}$ but it does help with symptoms of stress leakage. Advice should be given with regards to fluid intake, especially in curtailing fluid intake in the evening should nocturia be a problem. Again, evidence is lacking though the National Institute for Health and Clinical Excellence (NICE) go on to also suggest a trial of caffeine reduction in women. ${ }^{29,30}$

Behavioural therapy is the first line treatment for both men and women.29 Its aim is to reduce urinary frequency, re-establish voluntary control and to increase bladder capacity. In the cognitively intact the technique of bladder re-training can be employed. This involves timed voiding and attempted suppression of urgency in the intervening time period. To suppress urgency patients are advised to keep still, either standing or sitting, till the sensation has passed. The manner in which patients quell this desire to void can vary; some prefer to relax whilst others actively contract their rectal muscles (as if attempting to hold in flatus). Should the urgency persist despite these measures patients go to the toilet to void. When patients are continent for 48-72 $\mathrm{h}$ the time period between voids is increased. The aim is to achieve voiding intervals of $3-4 \mathrm{~h}$ without leakage. However, this takes motivation and a degree of determination as successful bladder re-training may take up to a number of months to achieve. This is evidence to show that in cognitively intact, community dwelling elderly bladder re-training in conjunction with medication (such as anti-muscarinics) may be more effective than bladder re-training alone. ${ }^{31,32}$ 
For those with cognitive impairment bladder re-training is not practical. These patients tend to benefit from a prompted, or scheduled, voiding regime. The drawback with this, however, is that it requires motivation and continual vigilance on the part of the relatives or carers. In the case of nursing home or hospitalised patients this approach can be quite labour intensive. It comprises of regular observation of the patient to monitor whether they remain continent or have leaked; prompting to void on a pre-determined timed basis; and positive re-enforcement when patients void appropriately themselves.

\section{Drugs}

The mainstay of treatment for $\mathrm{OAB}$ is currently the anti-muscarinics. Since the symptoms of overactive bladder syndrome were thought to originate from overactive detrusor contractions, it was argued that drugs affecting contractility would alleviate symptoms. Activity in the detrusor muscle is initiated at muscarinic receptors (M3) and drugs designed to target these $\mathrm{M} 3$ receptors have been proven to be effective in decreasing urgency and incontinence. ${ }^{33}$ However, it has been suggested that, at therapeutic doses, these drugs do not significantly affect bladder contraction, ${ }^{34-36}$ suggesting alternative modes of action. Therefore, if this is so our understanding of the mechanisms through which antimuscarinics act, and in turn our understanding of the generation of the sensation of urge and urgency, is incomplete. There is currently research underway to examine these alternate potential mechanisms in an attempt to develop new treatments.

Although the role of anti-muscarinic medication in the elderly has been established the efficacy and side effect profiles of these drugs have largely been extrapolated from a younger population; one without the associated co-morbidities, poly-pharmacy and potentially decreased cognition. The vast majority of data from randomised controlled trials have excluded the elderly population either on age grounds alone or by virtue of their co-morbidities. Those trials including the elderly by and large do not report the results as a separate cohort. Therefore, in interpreting these data on safety and efficacy some degree of caution needs to be exercised. Side effects of anti-muscarinics on the whole include; dry mouth, constipation, blurred vision, dizziness, nausea, confusion, palpitations and insomnia. In the elderly, however, there is further concern as to effects upon cognitive function. Medications with anti-cholinergic or anti-muscarinic properties have been shown to be associated with lower cognitive function amongst community dwelling elderly people though they do not increase the risk of dementia. The elderly are already affected by age related cognitive impairment in addition to the incidence of dementia increasing substantially with age. Furthermore they could potentially already be on a medication with some anti-cholinergic or anti-muscarinic activity. As such the potential for exacerbating an underlying cognitive disorder or suffering from cumulative anti-muscarinic effects of medication is high. Therefore, the principle behind anti-muscarinic use in the elderly is to start with a low dose, increasing it slowly whilst keeping an objective record of cognitive function. Attempts should also be made to minimise potential drug interactions.

There are a number of anti-muscarinic medications on the market, the most established of which being oxybutynin. Randomised, placebo controlled studies have shown oxybutynin, ${ }^{37}$ tolterodine ${ }^{38}$ solifenacin,${ }^{39}$ trospium chloride ${ }^{40}$ and darifenacin ${ }^{41}$ to reduce episodes of urge related leakage in the elderly. With regards to cognitive function trospium chloride and darifenacin seem to have less of a detrimental impact. In the case of darifenacin this may be related to its selectivity for the M3 receptor with little selectivity for the M1 receptor. Trospium Chloride, unlike the other tertiary amine anti-muscarinics, is a heavier quaternary amine and as such does not cross the blood brain barrier. ${ }^{42}$ The role of anti-muscarinics in the presence of anti-cholinesterases is unclear. There is an association with increased rates of $\mathrm{OAB}$ after the prescription of anti-cholinesterases, ${ }^{43}$ though there is little clear literature describing the effects of co-prescription.

\section{Intravesical botulinum toxin}

Botulinum neurotoxin type-A (BoNT-A) is one of seven sub-types of a potent biological toxin produced by the bacterium Clostridium botulinum. BoNT-A acts upon peripheral cholinergic nerve endings inhibiting acetylcholine release. ${ }^{44}$ First described by Schurch and Stöhrer, ${ }^{45}$ it has rapidly become used as a treatment for $\mathrm{OAB}$ in cases unrefractory to more conservative measures or where the side effects of anti-muscarinics were intolerable. It is cystoscopically injected into the bladder and gives symptomatic relief for approximately 6 months. ${ }^{46}$ The downside, however, is the small but significant risk of retention necessitating either a long term indwelling urethral catheter or for the patient to be taught intermittent self catheterisation.

\section{Future therapies}

In recent years the bladder has been shown to demonstrate a number of structures and cells that illustrate a complex interaction between the urothelium and suburothelial layers. A number of non-cholinergic mechanisms have also been demonstrated that may be involved in the generation of sensation and the modulation of bladder activity. Adenosine triphosphate, nitric oxide and acetylcholine have all been shown to be released from the urothelium in response to stretch. With their corresponding receptors found in the suburothelial layers upon structures such as interstitial cells, ganglia and afferent nerve fibres. With these likely to be involved in the generation of sensation a number of therapies are being developed to target these mechanisms. Unfortunately, potassium-channel openers have failed to show any efficacy. However, Aprepitant, an NK-1-receptor antagonist used for treatment of chemotherapy-induced nausea and vomiting was found to significantly improve symptoms of $\mathrm{OAB}$ in postmenopausal women with a history of urgency related leakage. 3 adrenergic receptors have been found predominantly in the human detrusor and there is convincing evidence that they have an important role in both normal and neurogenic bladders. A number of 3 -AR-selective agonists, including GW427353, YM178, and KUC7483, are currently being evaluated as a potential treatment for $\mathrm{OAB}$ in humans.

\section{Conclusions}

Overactive bladder syndrome is a common problem in the older age group that can seriously effect quality of life. It raises challenges in the assessment and treatment of the patient with attention needed to be given to the presence of co-existent disease, cognition, patient motivation and the potential negative effects of pharmacological treatment. Though with the correct approach a substantial amount patients should derive some benefit.

\section{References}

1. Abrams P, Cardozo L, Falls M et al. The standardisation of terminology of lower urinary tract function: report from the Standardisation Sub-Committee of the International Continence Society. Neurourol Urodyn 2002;21:167-78.

2. Stewart WF, Van Rooyen JB, Cundiff GW, et al. Prevalence and burden of overactive bladder in the United States. World J Urol 2003;20:327-36.

3. Horrocks S, Somerset M, Stoddart H, Peters TJ. What prevents older people from seeking treatment for urinary incontinence? A qualitative exploration of barriers to the use of community continence services. Fam Pract 2004;21:689-96.

4. Shaw C, Tansey R, Jackson C, et al. Barriers to help seeking in people with urinary symptoms. Fam Pract 2001;18:48-52. 
5. Norton PA, MacDonald LD, Sedgewick PM, Stanton SL. Distress and delay associated with urinary incontinence, frequency and urgency in women. BMJ 1988;297:1197-89.

6. Thom DH, Haan MN, van den Eeden SK. Medically recognised urinary incontinence and risks of hospitalisation, nursing home admission and mortality. Age Ageing 1997;26:367-74.

7. Milsom I, Abrams P, Cardozo L, et al. How widespread are the symptoms of an overactive bladder and how are they managed? A population based prevalence study. BJU Int 2001; 87: 760-6.

8. Giannakouris K. Ageing characterises the demographic perspectives of the European societies, 2008. Available from: www.Eurostat.ec.europa.eu

9. Ganz ML, Smalarz AM, Krupski TL, et al. Economic costs of overactive bladder in the United States. Urology 2010;75:526-32, 532.el-18.

10. Malone-Lee J, Wahedna I. Characterisation od detrusor contractile function in relation to old age. Br J Urol 1993;72:873-80.

11. Yoshida M, Miyamae K, Iwashita H, et al. Management of detrusor dysfunction in the elderly: changes in acetylcholine and adenosine triphosphate release during ageing. Urology 2004;63:S17-23.

12. Gomez-Pinilla PJ, Pozo MJ, Camello PJ. Aging differentially modifies agonist evoked mouse detrusor contraction and calcium signals. Age (Dordr) 2011;33:81-8.

13. Mansfield KJ, Liu L, Mitchelson FJ, et al. Muscarinic receptor subtypes in human bladder detrusor and mucosa, studied by radioligand binding and quantitative competitive RT-PCR: changes in ageing. Br J Pharmacol 2005;144:1089-99.

14. Rosenberg LJ, Griffiths DJ, Resnick NM. Factors that distinguish continent from incontinent older adults with detrusor overactivity. J Urol 2005;74:44-50.

15. Tromp AM, Pluijm SM, Smit JH, et al. Fall risk screening test: a prospective study on predictors for falls in community dwelling elderly. J Clin Epidemiol 2001;54:837-44.

16. Oliver D, Daly F, Finbarr M. Risk factors and risk assessment tools for falls in hospital inpatients: a systematic review. Age Ageing 2004;33:122-30.

17. Wagner TH, Hu TW, Bentkover J, et al. Health related consequences of overactive bladder. Am J Manag Care 2002:8:S598-607.

18. Herzog AR, Kiokno AC, Fultz NH. Urinary incontinence: medical and psychosocial aspects. Annu Rev Gerontol Geriatr 1989;9:74-119.

19. Pannill FC, Wiiliams TF, Davis R. Evaluation and treatment of urinary incontinence in long term care. J Am Geriatr Soc 1988;36:902-10.

20. Schröder A, Abrams P, Andersson KE, et al.
Guidelines on urinary incontinence. European Association of Urology. Online guidelines 2010, Available from: http:/www.guideline.gov

21. Robinson D, Cardozo L, Terpstra G, et al. A randomized doubleblind placebo-controlled multicentre study to explore the efficacy and safety of tamsulosin and tolterodine in women with overactive bladder syndrome. BJU Int 2007;100:840-5.

22. Cardozo L, Robinson D. Special considerations in premenopausal and postmenopausal women with symptoms of overactive bladder. Urology 2002;60:S64-71.

23. Cardozo L, Lose G, McClish D, Versi E. A systematic review of the effects of estrogens for symptoms suggestive of overactive bladder. Acta Obstet Gynecol Scand 2004; 83:892-7.

24. Nicolle LE. Asymptomatic bacteruria in the elderly. Infect Dis Clin North Am 1997; 11:647-62.

25. Helstrom PM, Sjoquist A. Involvement of opioid and nicotinic receptors in rectal and anal reflex inhibition of urinary bladder motility in cats. Acta Physiol Scand 1988; 133:559-62.

26. Dallosso HM, McGrother CW, Matthews RJ, et al. The association of diet and other lifestyle factors with overactive bladder and stress incontinence: a longitudinal study in women. BJU Int 2003;92:69-77.

27. Subak LL, Wing R, West DS, et al. Weight loss to treat urinary incontinence in overweight and obese women. $\mathrm{N}$ Engl $\mathrm{J}$ Med 2009;360:481-90.

28. Brown JS, Wing R, Barrett-Connor E, et al. Lifestyle intervention is associated with lower prevalence of urinary incontinence: the Diabetes Prevention Program. Diabetes Care 2006;29:385-90.

29. National Institute for Health and Clinical Excellence. Urinary incontinence: the management of urinary incontinence in women. Clinical guideline 40, 2006. Available from: www.nice.org.uk/nicemedia/pdf/CG40fullguideline.pdf

30. Hannestad YS, Rortveit G, Dalveit AK. Are smoking and other lifestyle factors associated with female incontinence? The Norwegian EPINCONT Study. BJOG 2003;110:247-54.

31. Burgio K, Locher JL, Goode PS, et al. Behavioural vs drug treatment for urinary urge incontinence in older women: a randomised control trial. JAMA 1998;280: 19952000.

32. Burgio K, Locher JL, Goode PS. Combined behavioural and drug therapy for urge incontinence in older women. J Am Geriatr Soc 2000;48:370-4.

33. Chapple C, Khullar V, Gabriel Z, Dooley JA. The effects of antimuscarinic treatments in Overactive Bladder: A systematic review and meta-analysis. Eur Urol 2005;48:5-26.

34. Andersson KE, Arner A. Urinary bladder contraction and relaxation: physiology and pathophysiology. Physiol Rev 2004;84:93586.

35. Andersson K-E, Yoshida M. Antimuscarinics and the Over Active DetrusorWhich is the main mechanism of action? European Urology 2003;43:1-5.

36. Finney S, Andersson KE, Gillespie JI, Stewart LH. Antimuscarinic drugs in detrusor overactivity and the overactive bladder syndrome: motor or sensory actions? BJU Int 2006;90:503-7.

37. Homma J, Paick JS, Lee JG, et al. Clinical efficacy and tolerability of extended-release tolterodine and immediate release oxybutynin in Japanese and Korean patients with an overactive bladder: a randomized, placebo-controlled trial. BJU Int 2003;92:741-7.

38. Malone-Lee JG, Walsh JB, Maugourd MF. Tolterodine: a safe and effective treatment for older patients with overactive bladder $\mathrm{J}$ Am Geriatrics Soc 2001;49:700-5.

39. Chapple CR, Rechberger T, Al Shukri S, et al. Randomized, double-blind placebo- and tolterodine-controlled trial of the once daily antimuscarinic agent solifenacin in patients with symptomatic overactive bladder. BJU Int 2004;93:303-10.

40. Rudy D, Cline K, Harris R, et al. Multicenter phase III trial studying trospium chloride in patients with overactive bladder. Urology 2006;67:275-80.

41. Foote J, Glavind K, Kralidis G, Wyndaele JJ. Treatment of overactive bladder in the older patient: pooled analysis of three phase III studies of darifenacin, an M3 selective receptor antagonist. Eur Urol 2005 48:4717.

42. Todorova A, Vonderheid-Guth B, Dimpfel W. Effects of tolterodine, trospium chloride and oxybutynin on the central nervous system. J Clin Pharmacol 2001;41:636-44.

43. Hashimoto M, Imamura T, Tanumikai S, et al. Urinary incontinence: an unrecognised adverse effect with donepezil. Lancet 2000;356:568.

44. Burgen A, Dickens F, Zatman LJ. The action of botulinum toxin on the neuromuscular junction. J Physiol (Lond) 1949;109:10-24.

45. Schurch B, Stöhrer M, Kramer G, et al. Botulinum A toxin for treating detrusor hyperreflexia in spinal cord injured patients: A new alternative to anticolinergic drugs? Preliminary results. J Urol 2000;164:692-7.

46. Werner M, Schmid DM, Schussler B. Efficacy of botulinum-A toxin in the treatment of detrusor overactivity incontinence: a prospective nonrandomised study. Am J Obstet Gynecol 2005;192:1735-40. 